\title{
Inserting Photovoltaic Solar Energy to an Automated Irrigation System
}

\author{
J.P. Reges \\ Department of Renewable Energy \\ Federal Institute of Education, Science \\ and Technology of Ceara
}

\author{
E.J. Braga \\ Department of Industry \\ Federal Institute of Education, Science \\ and Technology of Ceara \\ A.R. de Alexandria \\ Department of Renewable Energy \\ Federal Institute of Education, Science \\ and Technology of Ceara
}

\author{
L.C. dos S. Mazza \\ Department of Industry \\ Federal Institute of Education, Science \\ and Technology of Ceara
}

\begin{abstract}
Photovoltaic solar energy has been gaining market share over the years due to lower prices and to a significant incentive from the government. It is a clean, static and promising energy source, and such technology has been applied to various applications. This paper presents a prototype of an automated irrigation system for later installation on the field. After the prototype development, we analyzed the use of a previously built photovoltaic microgeneration, in order to insert the electricity generated in the automated irrigation system. The photovoltaic microgeneration has an installed capacity of $2.76 \mathrm{kWp}$ and a battery bank with $24 \mathrm{~V}$. The integration of photovoltaic solar energy in the automated irrigation system represented a good application for family farming, minimizing water waste, besides representing the use of a renewable energy source.
\end{abstract}

\section{General Terms}

Photovoltaic solar energy, Automated irrigation system

\section{Keywords}

Automated irrigation, Solar photovoltaic, Microgeneration, Renewable energy

\section{INTRODUCTION}

The energy issue is a global concern, given the recurrent crises in the electricity sector. Over the past decade, the energy sectors of many countries endured intense changes with stimulus to the decentralization of power generation, giving the distribution network a central role in this new model. Energy generation plays a key role in human life, along with means of transportation, telecommunications, water and sanitation. However, both the generation and use of energy should be handled in a harmonious way and appropriate to the environment, so that natural resources can be used rationally and sustainably [3, 10].

From the point of view of supply, the oil crisis and precariousness in the availability of such source resulted in rise in the price of fossil fuels, thus increasing the operating costs of the electrical sector companies operating power plants fed by these inputs. However, new environmental requirements have forced companies in the sector to include environmental costs in their activities due to several inherent problems, such as expropriation, areas of flooding for hydroelectric reservoirs, acid rain caused by the emission of carbon dioxide from thermal power plants and radiation by accidents in nuclear power plants [29 31].

Therefore, we need to use renewable energy sources, which are clean and less aggressive to nature and to humanity. This demands a technological domain in the exploitation of these new energy sources, reducing costs of manufacturing, installation and maintenance of related equipment. One of the most promising renewable energies being exploited by man is the photovoltaic energy, both in electricity production in isolated systems and in systems connected to the power grid [2. 19].

The distributed generation with systems connected to the power grid differs from the centralized generation once it delivers energy directly to the distribution grid or where the consumer is located, even in an industrial area, in an office building or in remote regions. Moreover, this type of generation does not imply maximum or minimum volume generation, and can be formed by high-low power unit. Such impact will bring both positive and negative points, depending on the configuration of photovoltaic systems. However, the injected power can support the voltage profile and system stability [25, 29, 30].

Even though photovoltaic systems applied in distributed generation are less used than other generation technologies, they are gaining ground globally due to incentive programs and regulations, obtaining strong growth in the market. This type of energy generation from the sun presents itself as one of the most rational forms of electricity generation. Once static and silent, it is a promising technology for electricity generation, providing the possibility of installing photovoltaic systems near houses [10 34].

Residents of rural areas sometimes have no access to electricity because of distance from the distribution power grid. In this case, they can choose to install photovoltaic panels with an integrated battery system which, during the night, can also make use of electricity. In turn, residents who already have access to electricity in 
their homes could install photovoltaic panels in order to save money spent on electricity. Those who do not have a place available for installation of photovoltaic panels can install them on the roof of their homes [4 14].

\subsection{Motivation}

Photovoltaic technology is growing, and its main markets are in Japan, Germany, Spain and the United States. Brazil could become a major promising country in this energy matrix, which has not happened yet because of the high cost of this technology and the lack of incentive by the government. Creating a mechanism to encourage the inclusion of photovoltaic energy in the Brazilian energy matrix will promote sustainable regional development, particularly for its characteristic of distributed generation. That will help the social and economic development of the country, once it presents low environmental impact and low rate of maintenance, is static and silent and can be installed near the consumption point, generating electricity immediately after installation or enabling, if necessary, their resettlement elsewhere. Some factors restrict the use of this technology, such as the high cost of photovoltaic modules, the growing worldwide manufacturing of photovoltaic modules and its no operation during the night. However, future generations will benefit from the use of clean and sustainable energy sources in order to contribute to the preservation of the environment, speeding up implementation of photovoltaic energy in the Brazilian energy market.

\subsection{Objective}

This work aims to study and develop a project that uses the electricity generated by a photovoltaic system for powering the proposed automated irrigation system, thus harmonizing with the automation environment.

\section{THEORETICAL BACKGROUND}

\subsection{Photovoltaic Energy}

In recent years, there was an increase in the use of alternative energy sources to complement the global energy matrix. However, such sources of global renewable energy generation have impacts and constraints, imposing some limitations. These limits are important for the planning and design of sustainable energy policies, demanding specialized studies for obtaining good performances in the installation of systems, in order to avoid serious consequences. Renewable energy sources are classified as hydro, thermal solar, photovoltaic solar, wind, ocean, geothermal and biomass. These sources use natural resources such as wind, water, solar radiation and heat as the operating principle for its generation. Hence, the applications of renewable energy sources are quite diverse and have been sought by several users [9, 13, 33].

The basic photovoltaic unit is called a solar cell, which together in groups form the photovoltaic panels, interconnected elements that compose the electric generator of a photovoltaic installation. The panels convert radiation into electrical energy by the photovoltaic effect. Such a phenomenon can be done because the panel is composed of semiconductor materials with specific properties.

Its production of electricity is the photovoltaic effect based on direct or indirect conversion of sunlight. The direct sunlight is extremely important for the generation of photovoltaic energy once the indirect approach does not produce an ideal performance to the system. Therefore, the panels should be able to capture the maximum amount of solar radiation during the day [8] 35].
Since the conversion of solar energy to electrical energy is accomplished by converting the radiation into electrical energy, the higher the incidence of solar rays on the panel, the greater will be the power generated by the photovoltaic system. There are some methods used for increasing energy production, such as solar trackers, which provide a performance better than those with fixed angle due to the amount of direct radiation on the panels [22, 38].

In power generation, some concepts are fundamental, such as solar radiation that is transmitted to our planet through space as electromagnetic radiation. The incidence of this radiation on the photovoltaic modules cause the photovoltaic effect, which is the operating basis of solar photovoltaic systems. From this transformation of solar radiation into electrical energy, a potential difference arises, which is an electrical voltage [6, 9].

Solar radiation suffers the influence of atmospheric air, clouds and pollution before reaching the ground. Hence, it is necessary that the photovoltaic panels are properly installed for capturing as much solar energy as possible. The classification regarding the connection to the power grid is of three types: isolated generators (off-grid), network-connected generators (Grid-tie) and hybrid generators [1]. The off-grid generators are those with no connection to the electrical distribution network. These systems are usually installed in places not served by power distribution companies, thus requiring the use of a battery bank to store the generated energy and to provide it during the period of no solar radiation. They are mainly composed of photovoltaic panels, charge controller, batteries and inverters, as shown in Figure 1$][1]$.

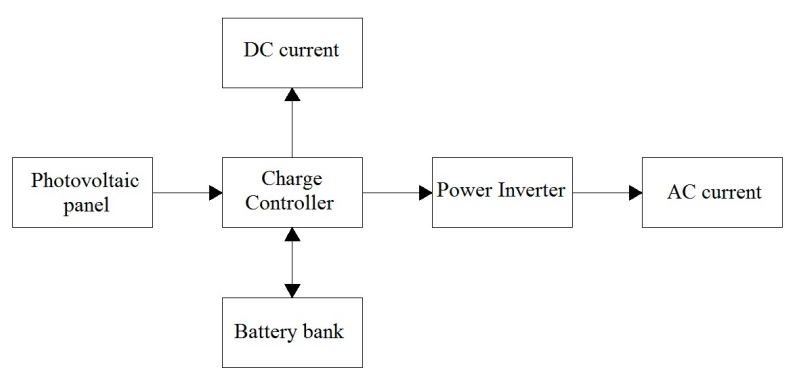

Fig. 1. Scheme of an isolated photovoltaic system powering DC and AC loads. Source: Author.

The Grid-tie generators are effectively connected to the public power grid. Once they are directly injected into the power grid, there is no need for battery bank. They are basically composed of the photovoltaic panel and the inverter, besides the components of control, protection and monitoring of the energy generation [1]. The photovoltaic park of Sarnia, in Canada, is an example of a large centralized photovoltaic plant with an installed capacity of $80 \mathrm{MWp}$ [12], as shown in Figure 2]

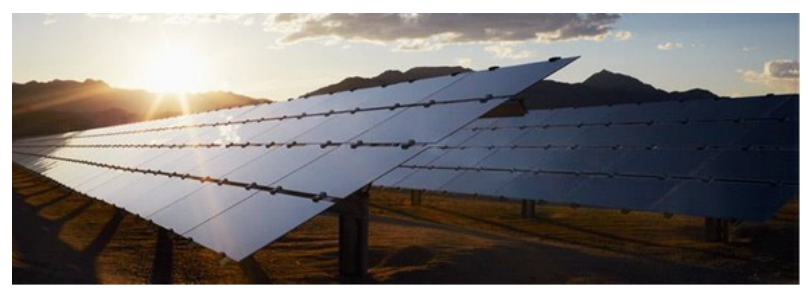

Fig. 2. Photovoltaic park of Sarnia, in Canada. Source: [12]. 
Hybrid generators are isolated systems operating together with other generators such as wind, gas, diesel, coal, nuclear, etc., as shown in Figure 3 In some cases, this union may be more beneficial than a photovoltaic system operating independently, since it promotes a reduction of the installed power of solar panels, thereby reducing the total costs [1].

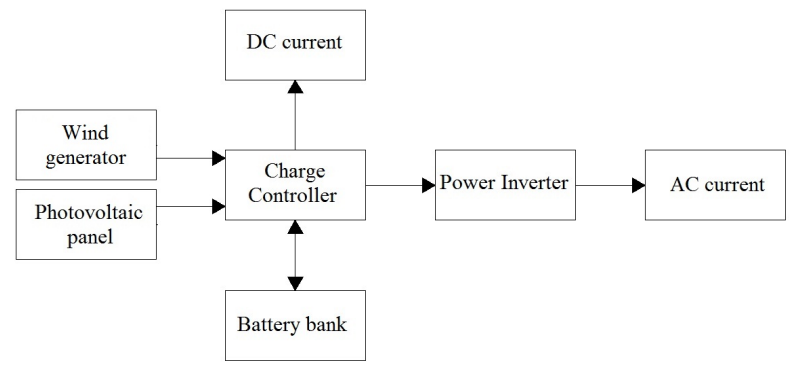

Fig. 3. Scheme of a hybrid photovoltaic system powering DC and AC loads. Source: Author.

\subsection{Automated Irrigation System}

The agricultural industry is interested in improving its production process in order to reduce spending on labor, energy, water waste in irrigation, excessive use of pesticides, fertilizers, among others, and reductions in these costs will increase profit. One of the solutions is applying automation in the farm, through an interdisciplinary work of distinct areas, which can bring positive results [20,36].

Some automated systems are controlled by Programmable Logic Controller (PLC), a technically viable alternative able to control and monitor processes such as the irrigation system, amount of energy used, pesticide use etc. [5]. Other automated systems may be controlled by microcontrollers, such as Arduino ${ }^{\mathbb{R}}$, which use Atmega family's chip in their microcontrollers [26]. This system is flexible for various electronic components providing interconnection and resolving various problems.

Due to the shortage of water resources, hydropower is raising prices, thus demanding alternative sources for electricity generation. This represents a sustainable measure for various systems such as equipment supply in static, remote places, marine applications, parking, water pumping systems, electric vehicles, satellites, traffic systems etc. [16, 18].

According to the United Nations [28], it is estimated that there would be 10 billion people by 2100 . Such huge population demands efficient generation and use of electricity. In Brazil, the generation of electricity mostly comes from hydroelectric companies, hence water rationing is another factor that must be taken into consideration. Although in many cases the irrigation system is well planned and able to provide good results, the proper monitoring of the parameters of this process may be inefficient. Therefore, such monitoring may allow the responsible professional to manage the best action to predict risk of underuse or overuse of resources required for system operation [27].

Automated systems provide a great improvement in production processes. Besides reducing human-based problems, it will also reduce problems related to inadequate operation and/or to waste of any raw material. However, designing fully autonomous systems may sometimes not be a viable alternative due to complexity and to socioeconomic conditions [15].

The automation of irrigation is a very important step both for those who work directly with this process and for humanity in general, thereby minimizing water waste. New irrigation strategies have been constantly created, especially in regions where such resources are scarce, thus forcing the installation of modern irrigated crops systems. The installation of real-time sensors provides the linking of information about spatial and time development of biotic and abiotic stress, such as instructions of the irrigation system allowing producers to maximize the efficiency of the proper use of water, to generate sustainability and to decrease negative effects on the environment [11, 23, 39].

Some studies have shown methods to automate irrigation of certain crops. 37. carried out control through fuzzy logic, where data were acquired from sensors and then they applied pre-determined rules to appropriately control the irrigation time. 24 evaluated the performance of a real-time automation system for irrigation, demonstrating that it is possible to provide an accurate prediction of irrigation performance in order to potentially increase the robustness of the process.

7 created an automated irrigation system based on the status of two coefficients, soil and two cultures, Vitis vinifera (cv Godello and $\mathrm{cv}$ Mencia). This process proved to be useful for real-time water management, triggering the irrigation system when the threshold value was reached.

\section{DISCUSSION}

For the automation of the irrigation system, we used a PLC composed of electronic components and programmable memory containing data and programs for reading and running instructions, thereby interacting with systems controlled by digital / analog input / output devices. This equipment can be programmed and used by people who do not have much technical knowledge.

The language used by this equipment is the relay diagrams language programming (ladder diagram). The main function of the program in ladder language is control the outputs drive, depending on the logical combination of the input contacts. A program in ladder language comes close to a diagram of electrical contacts, where the graphic symbols represent the actual devices and the way they would be connected.

The materials used for prototype simulation were: PLC CLIC02 WEG with 4 analog inputs and 6 analog outputs, CLIC02 PLC programming software version 3.3.1 and a testing bench for distributed control, as shown in Figure 4 By simulation, we could predict possible failures that may occur while running the project.

Programming follows according to Tables 1,2 and 3, where we demonstrate the nomenclatures used for each input and output of the system.

Table 1. Command pushbutton

\begin{tabular}{|c|c|}
\hline Pushbutton & Use \\
\hline I1 & External key of protection \\
\hline I2 & Energizing contacts \\
\hline I3 & Manual shutdown of the outputs \\
\hline I4 & Manual startup of EV1 (Q1) \\
\hline I5 & Manual startup of EV2 (Q2) \\
\hline I6 & Manual startup of EV3 (Q3) \\
\hline I7 & Manual startup of EV4 (Q4) \\
\hline
\end{tabular}

The key (I2) is responsible for connecting the whole process and starting up the timers that control the outputs. The timers (T1, T2, $\mathrm{T} 3$ and T4) control the time interval at which each electrovalve will be switched on, whereas the timer (T5) is responsible for energizing the method and for repeating the system. In programming, there 


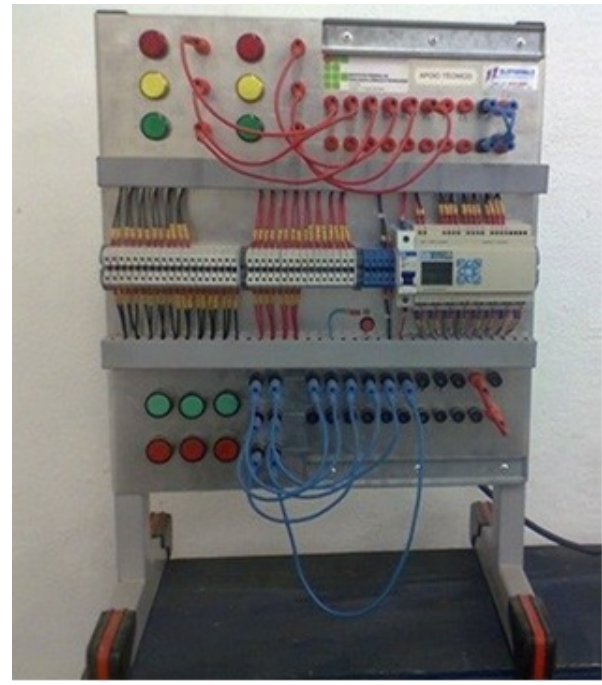

Fig. 4. Testing bench used for simulation. Source: Author.

Table 2. Digital outputs

\begin{tabular}{|c|c|}
\hline Output & Use \\
\hline Q1 & Electrovalve 1 (EV1) \\
\hline Q2 & Electrovalve 2 (EV2) \\
\hline Q3 & Electrovalve 3 (EV3) \\
\hline Q4 & Electrovalve 4 (EV4) \\
\hline
\end{tabular}

Table 3. Analog outputs

\begin{tabular}{|c|c|}
\hline Timer & Use \\
\hline T1 & Starts up the output Q1 (set function). \\
\hline T2 & $\begin{array}{c}\text { Starts up the output Q2 (set function), } \\
\text { shuts down the output Q1 (reset function). }\end{array}$ \\
\hline T3 & $\begin{array}{c}\text { Starts up the output Q3 (set function), } \\
\text { shuts down the output Q2 (reset function). }\end{array}$ \\
\hline T4 & $\begin{array}{c}\text { Starts up the output Q4 (set function), } \\
\text { shuts down the output Q3 (reset function). }\end{array}$ \\
\hline T5 & Responsible for energizing the other timers. \\
\hline
\end{tabular}

are the set and reset commands of the electrovalves, allowing the user to start and stop the process manually. The key (I3) will be responsible for manual shutdown, while the keys (I4, I5, I6 and I7) refer to startup of each of the electrovalves.

The timer T5 is a special case, once it works through startup and shutdown pulses, directly controlled by the pushbutton (I2). In total, four electrovalves are switched on, and they remained on for a period of $\mathrm{x}$ hours each, resulting in $4 \mathrm{x}$ total hours of operation, and remaining switched off during a period set by the user. Then the process is repeated.

The schematic irrigation plant used in the project is shown in Figure 5. where the lines represent a polyethylene PVC pipe; $C B$ is the pump house where is the PLC and the pump bike, and (EV1, EV2, EV3 and EV4) are the electrovalves.

An off-grid microgeneration is currently installed in the unit of Teaching and Research (UEPE) of the Federal Institute of Education, Science and Technology of Cear (IFCE) - Campus Limoeiro do Norte. It is composed of 12 photovoltaic $230 \mathrm{~W}$ panels that generate a total of $2760 \mathrm{Wp}$ in ideal conditions, as shown in figure 6 The system also comprises 12 batteries of $2 \mathrm{~V}$ totaling a $24 \mathrm{~V}$ battery bank as shown in figure 7 , and they are connected to the panels by a charge controller. In the system output, there is an inverter that converts the $24 \mathrm{~V}$ (direct current) of the battery bank into $220 \mathrm{~V}$ (alternating current) for commercial use, enabling the support of the automated irrigation system proposed.

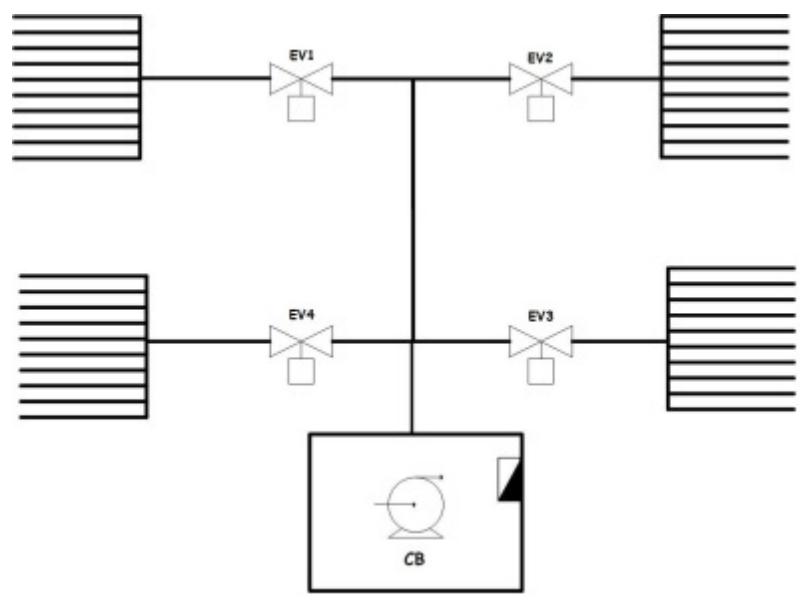

Fig. 5. Scheme of irrigation startup. Source: Author.

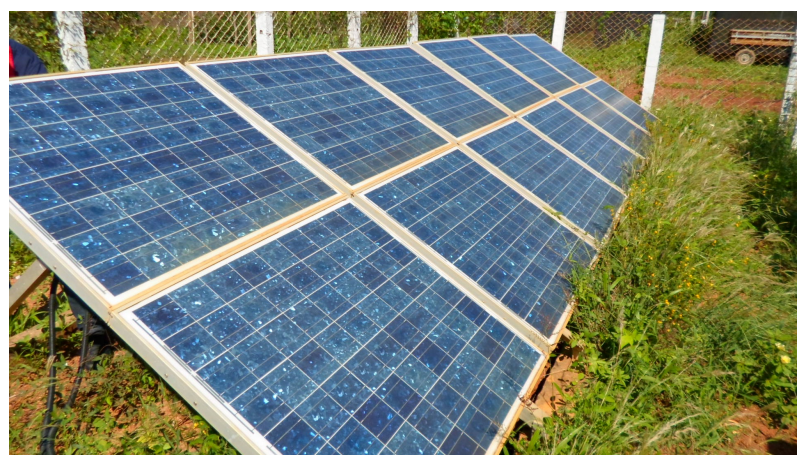

Fig. 6. Microgeneration installed at UEPE. Source: Author.

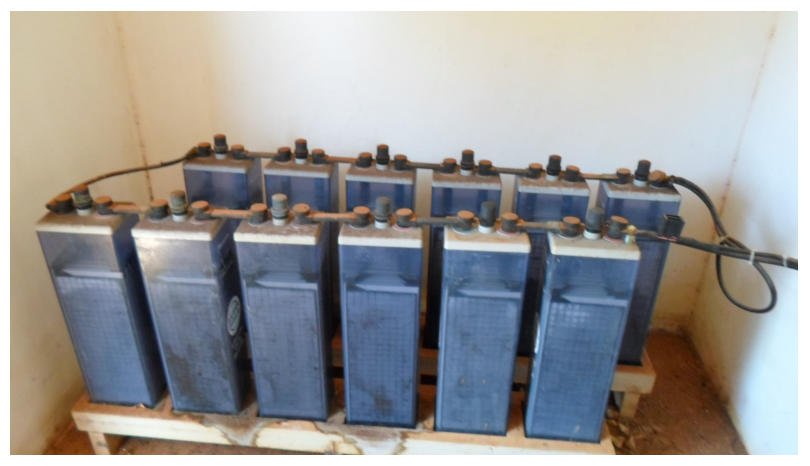

Fig. 7. Battery Bank. Source: Author.

When the system requires previously accumulated electrical energy, we need to use a battery bank, once the instantaneous power 
generated by the photovoltaic panels would not be enough to perform such task. If the power consumption increases, a new battery bank should be taken to supply the power demanded by the system. In this work, we did not use a battery bank, since we are dealing with a previously installed microgeneration, so we only used the electricity generated.

After testing the automated irrigation system, the possible faults are found, thus allowing the installation of the system on the field. Therefore, the connection between micro generation of electricity and the irrigation system will be taken, thus completing the project proposed in this paper.

\section{RESULT}

The data of solar radiation were obtained by Cearense of Meteorology and Water Resources Foundation (FUNCEME) [17], use a period of two months to simulate the power generation, the radiation values are demonstrated in Figure 8

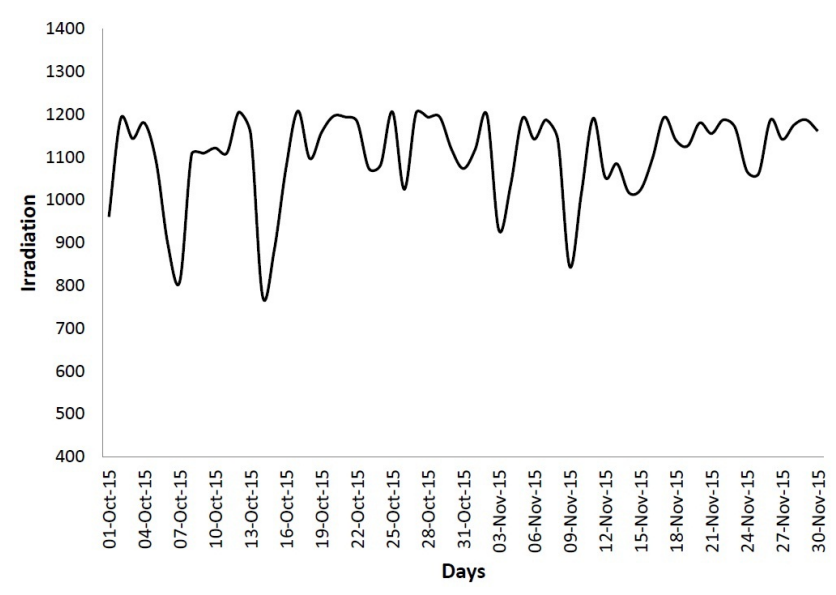

Fig. 8. Irradiation $\left(\mathrm{W} / \mathrm{m}^{2}\right)$. Source: Author.

After obtaining the irradiation of data, utilized the Psim [21, 32] software for the simulation of the microgeneration PV system installed. The microgeneration possess two pairs of six panels in series each panel possess a power of $230 \mathrm{Wp}$ so totaling a $2760 \mathrm{Wp}$ system. The equivalent circuit is demonstrated in Figure 9

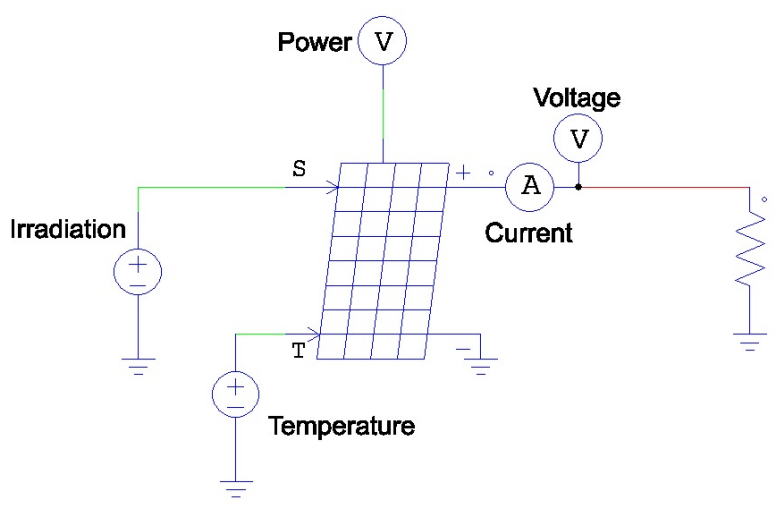

Fig. 9. Equivalent circuit photovoltaic microgeneration. Source: Author.
From the simulation it was possible to obtain the power values which are demonstrated in figure 10

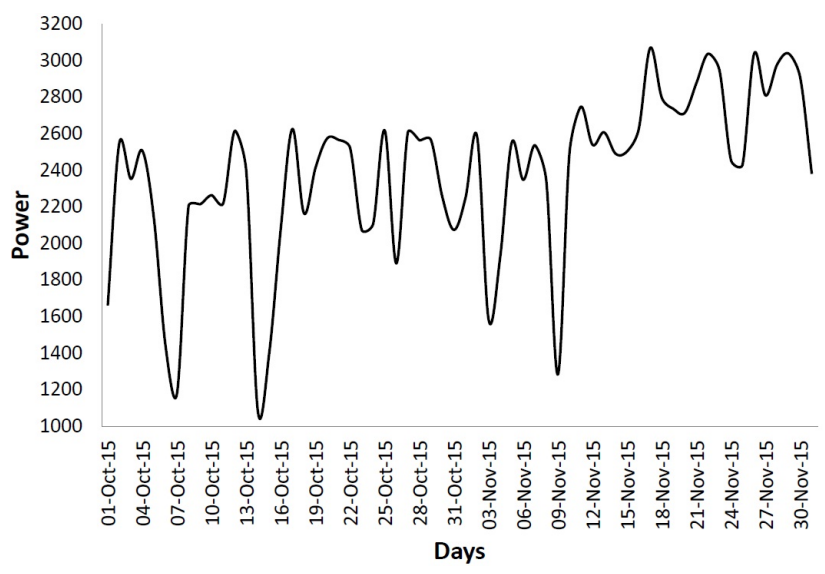

Fig. 10. Power (Wp). Source: Author.

All values obtained in the simulation are shown in table 4 According to simulation panels $2476,21 \mathrm{Wp}, 170,25 \mathrm{~V}$ and $13,82 \mathrm{~A}$ generated an average of over two months. The efficiency of the photovoltaic microgeneration is equal to $89.72 \%$.

\section{FINAL CONSIDERATIONS}

This paper proposes the use of electricity generated by a photovoltaic solar microgeneration in an automated irrigation system, thereby applying automation in favor of the environment and demonstrating that there are several types of applications, which only demand studies on their technical and economic feasibility. As seen in the the micro simulation yield was $89.72 \%$ in the generation of electricity. The simulation took into account the global radiation only, with no differentiation between direct radiation and diffuse radiation. The project shows a possibility of development for sustainable applications, by integrating different areas of knowledge to generate good results.

Currently, by investing in solar energy we are anticipating a sustainable awareness that will soon be an irreversible trend in the world, given the need to diversify our energy matrix and the benefits involved, such as: reduction of greenhouse gas emissions; improving quality of life; financial economy; real estate valuation; aesthetic appreciation; and investment in sustainable buildings.

\subsection{Future Work}

As future work, we highlight: the implementation of the automated irrigation system developed in this project; the design of a solar microgeneration system to meet the demand of the irrigation system; a monitoring system of variables both of irrigation and of microgeneration; and a socio-economic and environmental analysis of the implementation of the entire project.

\section{Acknowledgements}

We formally thank the Federal Institute of Education, Science and Technology of Ceara - Campus Limoeiro do Norte for the support, by providing us with the research environment, labs and the microgeneration of photovoltaic solar energy for carrying out this work. The authors thank the Post-Graduate Program in Renewable Energy from IFCE 
Table 4. Simulation results

\begin{tabular}{|c|c|c|c|c|}
\hline Date & $\begin{array}{c}\text { Irradiation } \\
\left(\mathbf{W} / \mathbf{m}^{2}\right)\end{array}$ & $\begin{array}{c}\text { Voltage } \\
\text { (V) }\end{array}$ & $\begin{array}{c}\text { Current } \\
\text { (A) }\end{array}$ & $\begin{array}{c}\text { Power } \\
\text { (Wp) }\end{array}$ \\
\hline $01 / 10 / 2015$ & 960.23 & 144.03 & 11.52 & 1659.69 \\
\hline $02 / 10 / 2015$ & 1189.63 & 178.45 & 14.28 & 2547.41 \\
\hline $03 / 10 / 2015$ & 1143.14 & 171.47 & 13.72 & 2352.17 \\
\hline $04 / 10 / 2015$ & 1179.78 & 176.97 & 14.16 & 2505.39 \\
\hline $05 / 10 / 2015$ & 1089.19 & 163.38 & 13.07 & 2135.41 \\
\hline $06 / 10 / 2015$ & 894.84 & 134.23 & 10.74 & 1441.34 \\
\hline $07 / 10 / 2015$ & 809.60 & 121.44 & 9.72 & 1179.81 \\
\hline $08 / 10 / 2015$ & 1106.25 & 165.94 & 13.27 & 2202.82 \\
\hline $09 / 10 / 2015$ & 1108.81 & 166.32 & 13.31 & 2213.04 \\
\hline $10 / 10 / 2015$ & 1121.10 & 168.17 & 13.45 & 2262.36 \\
\hline $11 / 10 / 2015$ & 1110.08 & 166.51 & 13.32 & 2218.12 \\
\hline $12 / 10 / 2015$ & 1205.12 & 180.77 & 14.46 & 2614.17 \\
\hline $13 / 10 / 2015$ & 1153.40 & 173.01 & 13.84 & 2394.59 \\
\hline $14 / 10 / 2015$ & 776.04 & 116.41 & 9.31 & 1084.03 \\
\hline $15 / 10 / 2015$ & 883.47 & 132.52 & 10.60 & 1404.94 \\
\hline $16 / 10 / 2015$ & 1076.45 & 161.47 & 12.92 & 2085.73 \\
\hline $17 / 10 / 2015$ & 1207.53 & 181.13 & 14.49 & 2624.62 \\
\hline $18 / 10 / 2015$ & 1096.50 & 164.47 & 13.16 & 2164.15 \\
\hline $19 / 10 / 2015$ & 1157.73 & 173.66 & 13.89 & 2412.60 \\
\hline $20 / 10 / 2015$ & 1195.39 & 179.31 & 14.34 & 2572.11 \\
\hline $21 / 10 / 2015$ & 1193.81 & 179.07 & 14.33 & 2565.32 \\
\hline $22 / 10 / 2015$ & 1183.26 & 177.49 & 14.20 & 2520.20 \\
\hline $23 / 10 / 2015$ & 1073.41 & 161.01 & 12.88 & 2073.98 \\
\hline $24 / 10 / 2015$ & 1082.07 & 162.31 & 12.98 & 2107.57 \\
\hline $25 / 10 / 2015$ & 1205.61 & 180.84 & 14.47 & 2616.28 \\
\hline $26 / 10 / 2015$ & 1024.76 & 153.71 & 12.30 & 1890.24 \\
\hline $27 / 10 / 2015$ & 1203.13 & 180.47 & 14.44 & 2605.52 \\
\hline $28 / 10 / 2015$ & 1193.27 & 178.99 & 14.32 & 2563.02 \\
\hline $29 / 10 / 2015$ & 1193.65 & 179.05 & 14.32 & 2564.64 \\
\hline $30 / 10 / 2015$ & 1118.10 & 167.71 & 13.42 & 2250.26 \\
\hline $31 / 10 / 2015$ & 1073.28 & 160.99 & 12.88 & 2073.46 \\
\hline $01 / 11 / 2015$ & 1117.90 & 167.69 & 13.41 & 2249.46 \\
\hline $02 / 11 / 2015$ & 1197.87 & 179.68 & 14.37 & 2582.82 \\
\hline $03 / 11 / 2015$ & 1393.65 & 209.05 & 16.72 & 3496.07 \\
\hline $04 / 11 / 2015$ & 1033.99 & 155.10 & 12.41 & 1924.44 \\
\hline $05 / 11 / 2015$ & 1190.21 & 178.53 & 14.28 & 2549.89 \\
\hline $06 / 11 / 2015$ & 1141.90 & 171.28 & 13.70 & 2347.07 \\
\hline $07 / 11 / 2015$ & 1186.88 & 178.03 & 14.24 & 2535.63 \\
\hline $08 / 11 / 2015$ & 1139.78 & 170.97 & 13.68 & 2338.36 \\
\hline $09 / 11 / 2015$ & 844.32 & 126.65 & 10.13 & 1283.18 \\
\hline $10 / 11 / 2015$ & 1017.31 & 172.90 & 14.40 & 2489.76 \\
\hline $11 / 11 / 2015$ & 1190.80 & 181.65 & 15.12 & 2746.55 \\
\hline $12 / 11 / 2015$ & 1052.99 & 175.10 & 14.50 & 2538.95 \\
\hline $13 / 11 / 2015$ & 1084.28 & 176.82 & 14.74 & 2606.33 \\
\hline $14 / 11 / 2015$ & 1017.21 & 172.90 & 14.40 & 2489.76 \\
\hline $15 / 11 / 2015$ & 1023.71 & 173.32 & 14.44 & 2502.74 \\
\hline $16 / 11 / 2015$ & 1096.22 & 177.44 & 14.78 & 2622.56 \\
\hline $17 / 11 / 2015$ & 1193.04 & 191.93 & 15.98 & 3067.71 \\
\hline $18 / 11 / 2015$ & 1139.01 & 183.24 & 15.26 & 2796.13 \\
\hline $19 / 11 / 2015$ & 1126.42 & 181.21 & 15.09 & 2734.64 \\
\hline $20 / 11 / 2015$ & 1768.35 & 284.49 & 23.69 & 6739.65 \\
\hline $21 / 11 / 2015$ & 1155.02 & 185.82 & 15.47 & 2875.29 \\
\hline $22 / 11 / 2015$ & 1186.83 & 190.93 & 15.90 & 3035.82 \\
\hline $23 / 11 / 2015$ & 1168.89 & 188.05 & 15.66 & 2944.77 \\
\hline $24 / 11 / 2015$ & 1067.05 & 171.66 & 14.30 & 2453.98 \\
\hline $25 / 11 / 2015$ & 1061.88 & 170.83 & 14.23 & 2430.28 \\
\hline $26 / 11 / 2015$ & 1186.75 & 190.92 & 15.90 & 3035.42 \\
\hline $27 / 11 / 2015$ & 1141.42 & 183.63 & 15.29 & 2807.96 \\
\hline $28 / 11 / 2015$ & 1175.41 & 189.10 & 15.75 & 2977.71 \\
\hline $29 / 11 / 2015$ & 1186.96 & 190.95 & 15.90 & 3036.49 \\
\hline $30 / 11 / 2015$ & 1160.82 & 186.75 & 15.55 & 2904.21 \\
\hline Mean & 1122.22 & 173.08 & 14.06 & 2476.21 \\
\hline
\end{tabular}

\section{REFERENCES}

[1] Md Arifujjaman, MT Iqbal, and JE Quaicoe. Reliability analysis of grid connected small wind turbine power electronics. Applied Energy, 86(9):1617-1623, 2009.

[2] Nicola Armaroli and Vincenzo Balzani. Energy for a sustainable world. Wiley-VCH, Weinheim, 2011.

[3] Muhammad Asif and Tariq Muneer. Energy supply, its demand and security issues for developed and emerging economies. Renewable and Sustainable Energy Reviews, 11(7):1388-1413, 2007.

[4] MMH Bhuiyan, M Ali Asgar, RK Mazumder, and M Hussain. Economic evaluation of a stand-alone residential photovoltaic power system in bangladesh. Renewable energy, 21(3):403410, 2000.

[5] William Bolton. Programmable logic controllers. Newnes, 2015.

[6] Richard Bube. Fundamentals of solar cells: photovoltaic solar energy conversion. Elsevier, 2012.

[7] JJ Cancela, M Fandiño, BJ Rey, and EM Martínez. Automatic irrigation system based on dual crop coefficient, soil and plant water status for vitis vinifera (cv godello and cv mencía). Agricultural Water Management, 151:52-63, 2015.

[8] Tian Pau Chang. The suns apparent position and the optimal tilt angle of a solar collector in the northern hemisphere. Solar energy, 83(8):1274-1284, 2009.

[9] Carlos De Castro, Margarita Mediavilla, Luis Javier Miguel, and Fernando Frechoso. Global solar electric potential: A review of their technical and sustainable limits. Renewable and Sustainable Energy Reviews, 28:824-835, 2013

[10] Ayhan Demirbas. Potential applications of renewable energy sources, biomass combustion problems in boiler power systems and combustion related environmental issues. Progress in energy and combustion science, 31(2):171-192, 2005.

[11] Mahir Dursun and Semih Ozden. Application of solar powered automatic water pumping in turkey. In International Conference on Electrical Energy and Networks (ICEEN), pages 52-57, 2011.

[12] Enbridge. Photovoltaic solar plant in sarnia, canada, 2015.

[13] Felix A Farret et al. Integration of alternative sources of energy. John Wiley \& Sons, 2006.

[14] Gerald Foley. Photovoltaic applications in rural areas of the developing world, volume 304. World Bank Publications, 1995.

[15] Robert A Frosch and Nicholas E Gallopoulos. Strategies for manufacturing. Scientific American, 261(3):144-152, 1989.

[16] Vasilis Fthenakis and Hyung Chul Kim. Life-cycle uses of water in us electricity generation. Renewable and Sustainable Energy Reviews, 14(7):2039-2048, 2010.

[17] Funceme. Cearense of meteorology and water resources foundation, 2015.

[18] Peter H Gleick. Water and conflict: Fresh water resources and international security. International security, pages 79-112, 1993.

[19] Joern Hoppmann, Michael Peters, Malte Schneider, and Volker H Hoffmann. The two faces of market support-how deployment policies affect technological exploration and exploitation in the solar photovoltaic industry. Research Policy, 42(4):989-1003, 2013. 
[20] Leo Horrigan, Robert S Lawrence, and Polly Walker. How sustainable agriculture can address the environmental and human health harms of industrial agriculture. Environmental health perspectives, 110(5):445, 2002.

[21] Md Rafiqul Islam, Youguang Guo, and Jianguo Zhu. A highfrequency link multilevel cascaded medium-voltage converter for direct grid integration of renewable energy systems. Power Electronics, IEEE Transactions on, 29(8):4167-4182, 2014.

[22] Soteris A Kalogirou. Design and construction of a one-axis sun-tracking system. Solar Energy, 57(6):465-469, 1996.

[23] Solomon H Katz, William Woys Weaver, et al. Encyclopedia of food and culture. Scribner, 2003.

[24] RK Koech, RJ Smith, and MH Gillies. Evaluating the performance of a real-time optimisation system for furrow irrigation. Agricultural Water Management, 142:77-87, 2014.

[25] JA Peças Lopes, N Hatziargyriou, J Mutale, P Djapic, and $\mathrm{N}$ Jenkins. Integrating distributed generation into electric power systems: A review of drivers, challenges and opportunities. Electric power systems research, 77(9):1189-1203, 2007.

[26] Micheal Margolis. Arduino cookbook. O`Reilly Media, Gravenstein Highway North, 2011.

[27] David J Molden and Timothy K Gates. Performance measures for evaluation of irrigation-water-delivery systems. Journal of irrigation and drainage engineering, 116(6):804-823, 1990.

[28] ONU. Novas estimativas da onu para a populao mundial em 2100, 2013.

[29] Richard L Ottinger, David Wooley, N Robinson, D Hodas, and S Babb. Environmental costs of electricity. 1990.

[30] Guido Pepermans, Johan Driesen, Dries Haeseldonckx, Ronnie Belmans, and William Dhaeseleer. Distributed generation: definition, benefits and issues. Energy policy, 33(6):787-798, 2005.

[31] Anne Power. Does demolition or refurbishment of old and inefficient homes help to increase our environmental, social and economic viability? Energy Policy, 36(12):4487-4501, 2008.

[32] Psim. The ultimate simulation environment for power conversion and control, 2015.

[33] J Reca, C Torrente, R López-Luque, and J Martínez. Feasibility analysis of a standalone direct pumping photovoltaic system for irrigation in mediterranean greenhouses. Renewable Energy, 85:1143-1154, 2016.

[34] PJ Sonneveld, GLAM Swinkels, BAJ Van Tuijl, HJJ Janssen, J Campen, and GPA Bot. Performance of a concentrated photovoltaic energy system with static linear fresnel lenses. Solar Energy, 85(3):432-442, 2011.

[35] Runsheng Tang and Tong Wu. Optimal tilt-angles for solar collectors used in china. Applied Energy, 79(3):239-248, 2004.

[36] Colin Thirtle, Lin Lin, and Jenifer Piesse. The impact of research-led agricultural productivity growth on poverty reduction in africa, asia and latin america. World Development, 31(12):1959-1975, 2003.

[37] Farid Touati, Mohammed Al-Hitmi, Kamel Benhmed, and Rohan Tabish. A fuzzy logic based irrigation system enhanced with wireless data logging applied to the state of qatar. Computers and electronics in agriculture, 98:233-241, 2013.

[38] Yingxue Yao, Yeguang Hu, Shengdong Gao, Gang Yang, and Jinguang Du. A multipurpose dual-axis solar tracker with two tracking strategies. Renewable Energy, 72:88-98, 2014.
[39] Yingying Zhang and Chunjing Yang. The application of automation control system in jiaxians constant pressure of water-saving irrigation. In 2015 International Conference on Advances in Mechanical Engineering and Industrial Informatics. Atlantis Press, 2015. 